\title{
Securing The Analysed Data Using Rjb21 Algorithm
}

\author{
R. Jaichandran ${ }^{1}$, S. Leelavathy ${ }^{3}$, E. Muhammed Mahsoos ${ }^{4}$, N. Nithya ${ }^{5}$, and B. Akash ${ }^{6}$ \\ 1,3,4,5,6 Department Of Computer Science And Engineering \\ Aarupadai Veedu Institute Of Technology \\ Vinayaka Mission'S Research Foundation \\ Paiyanoor-603 104, Tamil Nadu, India.
}

${ }^{1}$ rjaichandran@avit.ac.in, ${ }^{3}$ leelavathy@avit.ac.in, ${ }^{4}$ Mohammedmahsoos22@gmail.com, 5nithyan542@gmail.com,6akashb369@gmail.com

\author{
Dr. Avinash Sharma ${ }^{2 * *}$
}

${ }^{2}$ Professor, CSE Department, M.M. Deemed to be University, Mullana, Haryana, India, 133207

asharma@mmumullana.org

Corresponding Author: Dr. Avinash Sharma ${ }^{2} * *$

\begin{abstract}
.
The current world is information world; without this information can't make due in present stage. This information created more from web- based media; this media information is public information; This public infor- mation did not have well security; so we applying the proposed method and it has 2 steps; 1.Addition property in matrix; 2. Using prime numbers in qua- dratic equations. The proposed method gives well security while comparing with Salsa method.

Keywords. Associative Property, RJB21, Salsa, Encryption, Decryption.
\end{abstract}

\section{INTRODUCTION}

The current world is information world; without this information can't make due in present stage. This information created more from web-based media; this media information is public information; This public information did not have well security; so to conquer this matter we apply the Salsa strategy. This strategy effectively hack the information from the programmers. The additional rotations XOR for ChaCha is fault attack [1]. This author is used new hash concept for key guessing and halting condition [2]. Author was introduced thw bricklayer attack for analysis of ChaCha [3]. They mainly focuse the security for Double A [4]. They made new design for secure fast and flexible algorithm [5]. SRB18 method used to give security for data [6]. SRB21 method used to give security for data [7]. CBB21 method used to provide security for data [8]. CBB22 method used to provide security for data [9]. Introduced the new method RJB21( Rajaprakash Jaichandran and Bagath Basha) 21 for this problem.

\section{METHODS}

Associative property of addition (CP): This property discuss in Table 1 and Table 2 .

\section{ENCRYPTION}

"A is analyzed matrix"; and "B is secret matrix". [10] 
"Equation (1)"

"Equation (2)"

$$
\begin{aligned}
& \mathrm{A}=\left(\begin{array}{lll}
21 & 22 & 23 \\
24 & 25 & 26 \\
27 & 28 & 29
\end{array}\right) \mathrm{B}=\left(\begin{array}{lll}
32 & 34 & 33 \\
35 & 36 & 31 \\
37 & 39 & 38
\end{array}\right) \mathrm{C}=\left(\begin{array}{lll}
49 & 47 & 48 \\
46 & 44 & 45 \\
42 & 43 & 41
\end{array}\right) \\
& \mathrm{AP}=\left(\begin{array}{lll}
21+32 & 22+34 & 23+33 \\
24+35 & 25+36 & 26+31 \\
27+37 & 28+39 & 29+38
\end{array}\right)+\left(\begin{array}{ccc}
49 & 47 & 48 \\
46 & 44 & 45 \\
42 & 43 & 41
\end{array}\right) \\
& \mathrm{AP}=\left(\begin{array}{lll}
53 & 56 & 56 \\
59 & 61 & 57 \\
64 & 67 & 67
\end{array}\right)+\left(\begin{array}{lll}
49 & 47 & 48 \\
46 & 44 & 45 \\
42 & 43 & 41
\end{array}\right) \\
& \mathrm{AP}=\left(\begin{array}{lll}
53+49 & 56+47 & 56+48 \\
59+46 & 61+44 & 57+45 \\
64+42 & 67+43 & 67+41
\end{array}\right) \mathrm{AP}=\left(\begin{array}{lll}
102 & 103 & 104 \\
105 & 105 & 102 \\
106 & 110 & 108
\end{array}\right)
\end{aligned}
$$

"p=2,q=3, r=7"

"EM=36855654"

"Pairs $(3,6),(8,5),(5,6)$ and $(5,4) . "$

"Pair-1(3, 6)"

$$
\mathrm{EM}=\left(\begin{array}{lll}
102 & 103 & 104 \\
106 & 105 & 102 \\
105 & 110 & 108
\end{array}\right)
$$

"Pair-2(8, 5)"

$$
\mathrm{EM}=\left(\begin{array}{lll}
102 & 103 & 104 \\
106 & 105 & 108 \\
105 & 110 & 102
\end{array}\right)
$$

"Pair-3(5, 6)"

$$
\mathrm{EM}=\left(\begin{array}{lll}
102 & 103 & 104 \\
106 & 105 & 105 \\
108 & 110 & 102
\end{array}\right)
$$


TABLE 1. RJB21 Secure Encryption

\begin{tabular}{|l|l|}
\hline STEPS & \multicolumn{1}{|c|}{ RJB21 SECURE ENCRYPTION } \\
\hline i & "The data analyzed from social data". \\
\hline ii & "The data will form a matrix". \\
\hline iii & "The associative property (AP) is applied in the matrix AP \\
"AP $=A+(B+C)=(A+B)+C "(\mathbf{1})$
\end{tabular}

TABLE 2. RBJ21 Secure Decryption

\begin{tabular}{|l|l|}
\hline STEPS & \multicolumn{1}{|c|}{ RJB21SECURE DECRYPTION } \\
\hline i & "To analyse theprime in the given matrix". \\
\hline ii & "DM2 $=\left(-p \pm \sqrt{ }\left(p^{2}\right)-4 q r\right) / 2 a$. where DM2 is decrypted matrix 2" (3) \\
\hline iii & "To form a single row for merged numbers". \\
\hline iv & "To form a pair from right to left from Step 3". \\
\hline v & "All pair could be swapped cell values from given matrix". \\
vi & $\begin{array}{l}\text { "Minus the secret key matrixes C and B with the matrix DM1". } \\
D M 2=D M 1-C(\mathbf{4}) \\
\text { where DM2 is Decrypted Matrix 2 } \\
D M 3=D M 2-B(\mathbf{5}) \\
\text { where DM3 is Decrypted Matrix 3 }\end{array}$ \\
\hline
\end{tabular}

"Pair-4(5, 4)"

$$
\mathrm{EM}=\left(\begin{array}{lll}
102 & 103 & 104 \\
106 & 105 & 105 \\
108 & 110 & 102
\end{array}\right)
$$

\section{DECRYPTION}

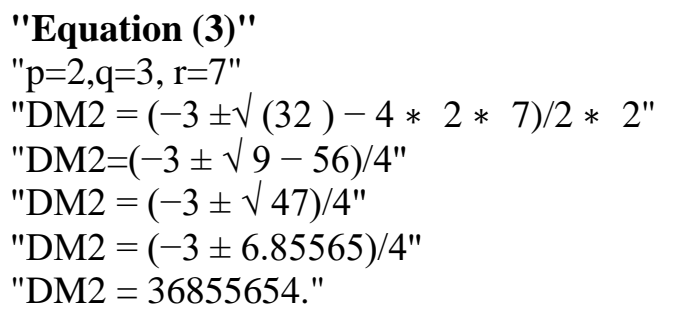

"Pair of numbers $(4,5),(6,5),(5,8)$, and $(6,3) . "$ 
"Pair-1 (4, 5)"

$$
\mathrm{DM} 1=\left(\begin{array}{lll}
102 & 103 & 104 \\
106 & 105 & 105 \\
108 & 110 & 102
\end{array}\right)
$$

"Pair-2(6, 5)"

$$
\mathrm{DM} 1=\left(\begin{array}{lll}
102 & 103 & 104 \\
106 & 105 & 108 \\
105 & 110 & 102
\end{array}\right)
$$

"Pair-3(5, 8)"

$$
\mathrm{DM} 1=\left(\begin{array}{lll}
102 & 103 & 104 \\
106 & 105 & 102 \\
105 & 110 & 108
\end{array}\right)
$$

"Pair-4(6, 3)"

$$
\mathrm{DM} 1=\left(\begin{array}{lll}
102 & 103 & 104 \\
105 & 105 & 102 \\
106 & 110 & 108
\end{array}\right)
$$

"Equation (4)"

$" \mathrm{DM} 2=\mathrm{DM} 1-\mathrm{C} "$

$$
\begin{aligned}
\mathrm{DM} 2 & =\left(\begin{array}{lll}
102 & 103 & 104 \\
105 & 105 & 102 \\
106 & 110 & 108
\end{array}\right)-\left(\begin{array}{lll}
49 & 47 & 48 \\
46 & 44 & 45 \\
42 & 43 & 41
\end{array}\right) \\
\mathrm{DM} 2 & =\left(\begin{array}{lll}
102-49 & 103-47 & 104-48 \\
105-46 & 105-44 & 102-45 \\
106-42 & 110-43 & 108-41
\end{array}\right) \mathrm{DM} 2=\left(\begin{array}{llll}
53 & 56 & 56 \\
59 & 61 & 57 \\
64 & 67 & 67
\end{array}\right)
\end{aligned}
$$




\section{"Equation (5)"}

$" \mathrm{DM} 3=\mathrm{DM} 2-\mathrm{B} "$

$$
\begin{gathered}
\text { DM3 }=\left(\begin{array}{ccc}
53 & 56 & 56 \\
59 & 61 & 57 \\
64 & 67 & 67
\end{array}\right)-\left(\begin{array}{lll}
32 & 34 & 33 \\
35 & 36 & 31 \\
37 & 39 & 38
\end{array}\right) \\
D M 3=\left(\begin{array}{lll}
53-32 & 56-34 & 56-33 \\
59-35 & 61-36 & 57-31 \\
64-37 & 67-39 & 67-38
\end{array}\right) \text { DM3 }=\left(\begin{array}{lll}
21 & 22 & 23 \\
24 & 25 & 26 \\
27 & 28 & 29
\end{array}\right)
\end{gathered}
$$

\section{CONCLUSION}

Prediction of an environmental parameter is possible using sensing [16-20] or IoT [21-23] mechanism but prediction of security is based on features of data or Big Data[24,25]. Different kinds of prediction possible using various techniques including ML [26,27].

The current world is information world; without this information can't make due in present stage. This information created more from web-based media; this media information is public information; This public information did not have well security; so we applying the RJB21 method and it has 2 steps; 1 .Ad- dition property in matrix; 2 . Using prime numbers in quadratic equations. The RJB21 method gives well security while comparing with Salsa method.

\section{REFERENCES}

[1] P. A. BABU AND J. J. THOMAS: A PRACTICAL FAULT ATTACK on ARX-like Ciphers with A CASE Study on CHACHA20, Wo. on Fa. Di. and To. in Cr. (2017), 33-40.

[2] S. V. D. KUMAR, S. PATRANABIS, J. BREIER, D. MUKHOPADHYAY, S. BHASIN, A. CHATTOPADHYAY, AND A. BAKS: Freestyle, A RANDOMIZED version of CHACHA for resisting offline brute-force AND DICTIONARY ATTACKS, IE. tr. on In. Fo. and Se. (2018).

[3] A. ADOMNICAI, J. J. A. FOURNIER, AND L. MASSON: BRICKLAYER ATTACK: A Side- CHANNEL ANALYSIS on the CHACHA QUARTER Round, Pr. in Cr. In., Le. No. in Co. Sc., Sp. 65-84.

[4] B. MAZUMDAR, S.K. S. ALI AND O. SINANOGLU: Power ANALYSIS ATTACKS on ARX: An APPLICATION to SALSA20, On-. Te. Sy. IE. (2015), 40-43.

[5] C. WATT, J. RENNER, N. POPESCU, S. CAULIGI, AND D. STEFAN: CT-WASM: Type- Driven Secure CRYPTOGRAPHY for theWeb Ecosystem, Pr. ACM Pr. La. PO. (2019), 77:1-77:29.

[6] C. BAGATH BASHA, S. RAJAPRAKASH: ENHANCING The Security Using SRB18 Method of Embedding Computing, Mir. and Mic 103125, (2020).

[7] C. B. BASHA, S. RAJAPRAKASH: Securing Twitter DATA Using Srb21 PHASE I Method- ology, Int. Jou. of Sci. and Tec. Res. 8(12) (2019), 1952-1955.

[8] C. B. BASHA, S. RAJAPRAKASH: Applying The CBB21 PHASE 2 Method For Securing Twitter ANALYSED DATA, Adv. In Mat. : Sci. Jou. 9(3) (2020), 1085-1091.

[9] C. B. BASHA, S. RAJAPRAKASH, V. V. A. HARISH, M. S. KRISHNA, K. PRABHAS: Securing Twitter ANALYSED DATA Using CBB22 Algorithm, Adv. In Mat. : Sci. Jou. 9(3) (2020), 1093-1100. 
[10] C. B. BASHA, K. SOMASUNDARAM: A COMPARATIVE Study of Twitter Sentiment ANAL- ysis Using MACHINE LEARNING Algorithms in Big DATA, Int. Jou. of Rec. Tec. and Eng. 8(1) (2019), 591-599.

[11]Somasekar, J. \& Sharma, A. \& Reddy, N. \& Reddy, Y.. (2020). IMAGE ANALYSIS FOR AUTOMATIC ENUMERATION OF RBC INFECTED WITH PLASMODIUM PARASITES-IMPLICATIONS FOR MALARIA DIAGNOSIS. Advances in Mathematics: Scientific Journal. 9. 1221-1230. 10.37418/amsj.9.3.48.

[12] A. SHARMA1 AND J. SOMASEKAR "Contrast Image Construction Technique for Medical Imaging" published in Advances in Mathematics: Scientific Journal (Adv. Math., Sci. J.) vol-9-no-6-2020 (pp 3325-3329)

[13] Rohini Goel, Avinash Sharma, and Rajiv Kapoor, "Object Recognition Using Deep Learning" published in Journal of Computational and Theoretical Nanoscience Vol. 16, 40444052, 2019

[14] Santosh, Mamta \& Sharma, Avinash. (2019). A Proposed Framework for Emotion Recognition Using Canberra Distance Classifier. Journal of Computational and Theoretical Nanoscience. 16. 3778-3782. 10.1166/jctn.2019.8250.

[15] Mamta Santosh, Avinash Sharma, "Facial Expression Recognition using Fusion of LBP and HoG Features" published in International Journal of Innovative Technology and Exploring Engineering (IJITEE) ISSN: 2278-3075, Volume-8 Issue-8 June, 2019

[16] Varsha, N. Kumar, Energy Efficient TABU Optimization Routing Protocol for WSN, Ingeniería Solidaria, Universidad Cooperativa de Colombia, Issue- 33, July 2020.

[17] G.Arora, A.Kumar, Versha, N.Kumar, "Swarm Intelligence based QoS optimized routing in WSN", Test Engineering \& Management, Vol.-82, 2020. pp-12880-12885.

[18] Varsha, M. B., Kumar, M., \& Kumar, N. Hybrid TABU-GA Search For Energy Efficient Routing In WSN. International Journal of Recent Technology and Engineering (IJRTE) ISSN: 2277-3878, Volume-8 Issue-4, November 2019. P.-3250-3256.

[18] Varsha, M. B., Kumar, M., \& Kumar, N. Development of QoS optimized routing using Artificial bee colony and TABU-GA with a mobile base station in Wireless Sensor Network, International Journal of Innovative Technology and Exploring Engineering (IJITEE) ISSN: 22783075, Volume-9 Issue-1, November 2019.

[19] Awadhesh Kumar Maurya,Varsha, Neeraj, Ajay Kumar, Neeraj Kumar, "Improved chain based cooperative routing protocol in wsn", FEST, Journal of Physics: Conference series, IOP Publishing, 1478,1-8, 13/05/2020.

[20] N. Kumar, A. Agrawal, R. A. Khan, "METHWORK: An Approach for Ranking in Research Trends with a Case Study for IoET, Recent advances in Computer Science and Communication (formerly Recent Patents on Computer Science), 2019.

[21] Neeraj Kumar; Paresh Goyal; Gayatri Kapil; Alka Agrawal; Raees A Khan, "Flood Risk Finder for IoT based Mechanism using Fuzzy Logic", Materials Today: Proceedings, Elsevier, 2020.

[22] Kumar, Neeraj, Alka Agrawal, and R. A. Khan. "Cost estimation of cellularly deployed IoTenabled network for flood detection." Iran Journal of Computer Science , issue 2, no. 1 (2019), Springer Nature: 53-64.

[23] V. Velvizhi; Satish R Billewar; Gaurav Londhe; Pravin Kshirsagar; Neeraj Kumar, "Big Data for Time Series and Trend Analysis of Poly Waste Management in India", Materials Today: Proceedings, Elsevier, 2020.

[24] G. Arora, A. K. Maurya, N. Kumar, A. K. Mishra, "Application of big data generated by IoT environment for HealthCare using Voice Recognition", International journal of research in engineering, IT and Social Sciences, vol.-08, issue-11, November 2018, page. 132-136.

[25] Manoj Diwakar, Amrendra Tripathi, Kapil Joshi, Minakshi Memoria , Prabhishek Singh, Neeraj kumar, "Latest Trends on Heart Disease Prediction using Machine Learning and Image Fusion", Materials Today: Proceedings,Elsevier, 2020.

[26] Parth Wadhwa; Aishwarya; Amrendra Tripathi; Prabhishek Singh; Manoj Diwakar; Neeraj Kumar, "Predicting the Time Period of Extension of Lockdown due to Increase 
European Journal of Molecular \& Clinical Medicine

in Rate of COVID-19 Cases in India using Machine Learning", Materials Today: Proceedings Elsevier, 2020. 